\title{
Movements of Media in Yvonne Rainer's Hand Movie (1966) and Richard Serra's Hand Catching Lead (1968)
}

Kyle Bukhari, Sarah Lawrence College

\begin{abstract}
This article focuses on two experimental films from the 1960s: Yvonne Rainer's Hand Movie (1966) and Richard Serra's Hand Catching Lead (1968). It scrutinizes the way both works exhibit a hybridized and indeterminate approach to artistic media. It offers an empirical reading of the films' movement and contextualizes them historically to move on to a theory of medium informed by Deleuze, Levinson, and Rajewsky. How does Rainer's move from the time-based media of dance and choreography, and Serra's move from the object arts of painting and sculpture, into the medium of film, advance our understanding of what is at stake aesthetically when boundaries of media are dissolved, transited, or displaced? Dance aesthetics requires that we show how movement gets translated into medium. I propose that the movement of media creates a displacement that is parallel to the displacement from the empirical to the theoretical in this article, where displacement becomes a form of reflection and critique.
\end{abstract}

Keywords: Yvonne Rainer, Richard Serra, experimental film, medium, hybridity

This article focuses on two experimental films from the 1960s: Yvonne Rainer's Hand Movie (1966) and Richard Serra's Hand Catching Lead (1968). I In particular, it scrutinizes and schematizes the way both works exhibit an indeterminate and hybridized approach to artistic media that brings the status of their respective aesthetic identities into question. Both films have been categorized within minimalist, 2 post-minimalist, 3 and post-modernist 4 aesthetics-classifications that themselves have sparked substantial debate. Each film has a similar ontological premise: a hand engaged in an activity, captured within the medium of film.5 This is particularly salient considering each film is a product of an artist that hails from a distinctly different disciplinary background. Rainer, a pivotal figure in American dance and founding member of the Judson Dance Theatre, redefined what could be considered dance to include everyday movements, working with objects, and task-oriented choreographies. She went on to generate an extensive oeuvre of films, poetry, and writing before returning to choreography in the 1990s. The American artist Serra, now known as a sculptor of large-scale works in rectilinear or torqued, undulating steel, was a multidisciplinary artist in the mid-1960s with an MFA in painting from Yale. His mixed media pieces 
purposely defied categorization, 6 incorporating rubber, neon tubing, lead, film and video, and even live animals as material.7

Rainer and Serra's arguably transgressive approach to the rules and conventions of their respective artistic media was not unusual for the post-minimalist artists whose work was often based in the investigative overlap between the object and temporal arts, a method that moved beyond modernist formal constraints and foregrounded materials and process. Art historian Benjamin Buchloh has suggested that within this interchange between media, the temporality embedded within process, gleaned from the performing arts, was repurposed and synthesized with the material nature of the plastic arts, giving way to new media hybridity.9 This rethinking of traditional conceptions of medium, what art historian Rosalind Krauss has defined as determined by: "specialized roles, methods of production, and conventional materials" arguably made performance, film, and video some of the most appropriate media to realize these new priorities.10 Krauss' definition of medium exemplifies how art and technology operate in tandem, and the way they have been theorized philosophically, from Walter Benjamin 11 to Marshall McLuhan. ${ }_{12}$ The availability of a new technological medium, in this case a hand-held Super 8 camera, simultaneously modified artistic production and destabilized entrenched aesthetic categories, absorbing the former into the new medium in one fell swoop, yet still bearing vestigial traces of the previous form embedded within, an idea that has been explored in depth by J. David Bolter and Richard A. Grusin with their notion of remediation, a concept that captures the particular paradoxes of media's immediacy and invisibility in our digital age.13

The questions that guide this article hinge on the idea of movement of and between media. I initially consider how an artist with a background and training in a more 'traditional' medium 14 such as dance, painting, or sculpture, branches out to test the waters of a secondary or even tertiary medium. I then examine how viewers perceive these works in their compliance or divergence with then-established conventions of medium specificity. How, for example, does Rainer's move from the time-based media of dance and choreography, and Serra's move from the object arts, i.e. painting and sculpture, into the medium of film, advance our understanding of what is at stake aesthetically when boundaries of media are dissolved, transited, or displaced? Is it only through the dissolution of medial boundaries that the identity of an individual medium becomes distinct? What does it mean to speak of a resulting hybridity? Is hybridity a static category composed of equal, heterogeneous parts, or is it rather a synthetic identity that is in a state of dynamic flux? Finally, how does knowledge of art and dance historical developments inform perception, and allow for aesthetic classification of component, or constituent media, of the artistic work or production we witness?

Divided into three sections, this article is structured by the organizing theme of movement, and progresses from the empirical towards ever-increasing levels of 
theoretical abstraction. Starting with brief descriptions of Rainer's Hand Movie and Serra's Hand Catching Lead, a nascent ontology that formally links the films comes into focus. I then deploy philosopher Gilles Deleuze's cinematic theory of the "movementimage" to support my claim that movement, and its very idea, are over-determining factors of both films.15 Where Deleuze's "theory of frame" provides a technical methodology to make visible previously unseen differences between the films, his notion of "out of field" (hors-champs) provides the possibility for an imaginative movement of the mind outside of what is optically perceptible on the screen, a move that I propose renders Rainer and Serra's obscured bodies not absent, but starkly present.

As mentioned above, the composition of the films and the experimental approach taken by the artists would tend to move the discussion towards notions of hybridity. Philosopher Jerrold Levinson's concept of "Gedanken" or "thought hybrids" helps support the movement thesis that conceptually underpins this project. 16 In my reading of Levinson, I posit that the directional movement toward the constituent media of a hybrid results in an aesthetic indeterminacy of hybrid forms. Within this indeterminacy, a conceptual dynamism becomes discernible, and I suggest that this aesthetic hybridity is itself the result of the movement of the media forms themselves, a process augmented by how we choose, consciously or not, to perceive them as hybridized works of art.

Terminology is not to be underestimated. The use of words like intermedial, intramedial, and transmedial, drawn from intermedial studies, show from a linguistic perspective how abstract movement implied in language can open a space or gap between concepts of media.17 Within this space, a theory of displacement can gain traction. This is key to my movement thesis, since it makes visible what is at stake when media can be seen not only as in motion, or hybridized, but ultimately in a state of perpetual displacement. A theory of displacement also points to the way the arts, as marginalized or commodified social practices, can be seen as displaced within society-stripped of their political power, or instrumentalized for commercial purposes. This is a larger, more complex issue that can only be gestured to here.

\section{Manual Ontologies}

Rainer filmed the $8 \mathrm{~mm}$ black and white film entitled Hand Movie (1966) with fellow Judson artist William Davis while confined to a hospital bed, recovering from surgery.18 It was her first film, and the first of a set that would become known as 5 Easy Pieces. Critically, it is one of the few film artifacts of her early work. For Rainer, these films were seen as experiments rather than finished art works; she now refers to them humorously as her "early boring short films." 19 This is despite their status as a rare visual record from a key period of artistic production that includes canonical works such as Parts of Some Sextets (1965), the penning of her infamous "No Manifesto" 
(1965), 20 the eponymous Trio A (1966), and The Mind as a Muscle (1968) in which Hand Movie was screened as well. 21

A brief analysis of Hand Movie proves fruitful for apprehending its structure, temporal unfolding, and subtle articulations that subvert the semiotic potentiality of gesture.22 Considered choreographically, the movements in Hand Movie tend to begin neutrally and escalate in complexity, before returning again to a flat 'start' position of the hand. Rainer deliberately shows the hand from all sides-suggesting a sculptural, threedimensional perspective. A single digit is often isolated from its relation to the rest of the hand; two fingers might interlock, allowing a new freedom for the other digits. At times the movement is barely perceptible: a gentle splaying of the palm and fingers, or slow curling and uncurling. Most striking in Rainer's articulation of her fingers is that she makes her digits appear as if they are autonomous units, no longer under the coordinating jurisdiction of the hand-and this gets messy-as they then appear to be involved with the task of untangling themselves-an action not normally associated with the everyday use of the hand.

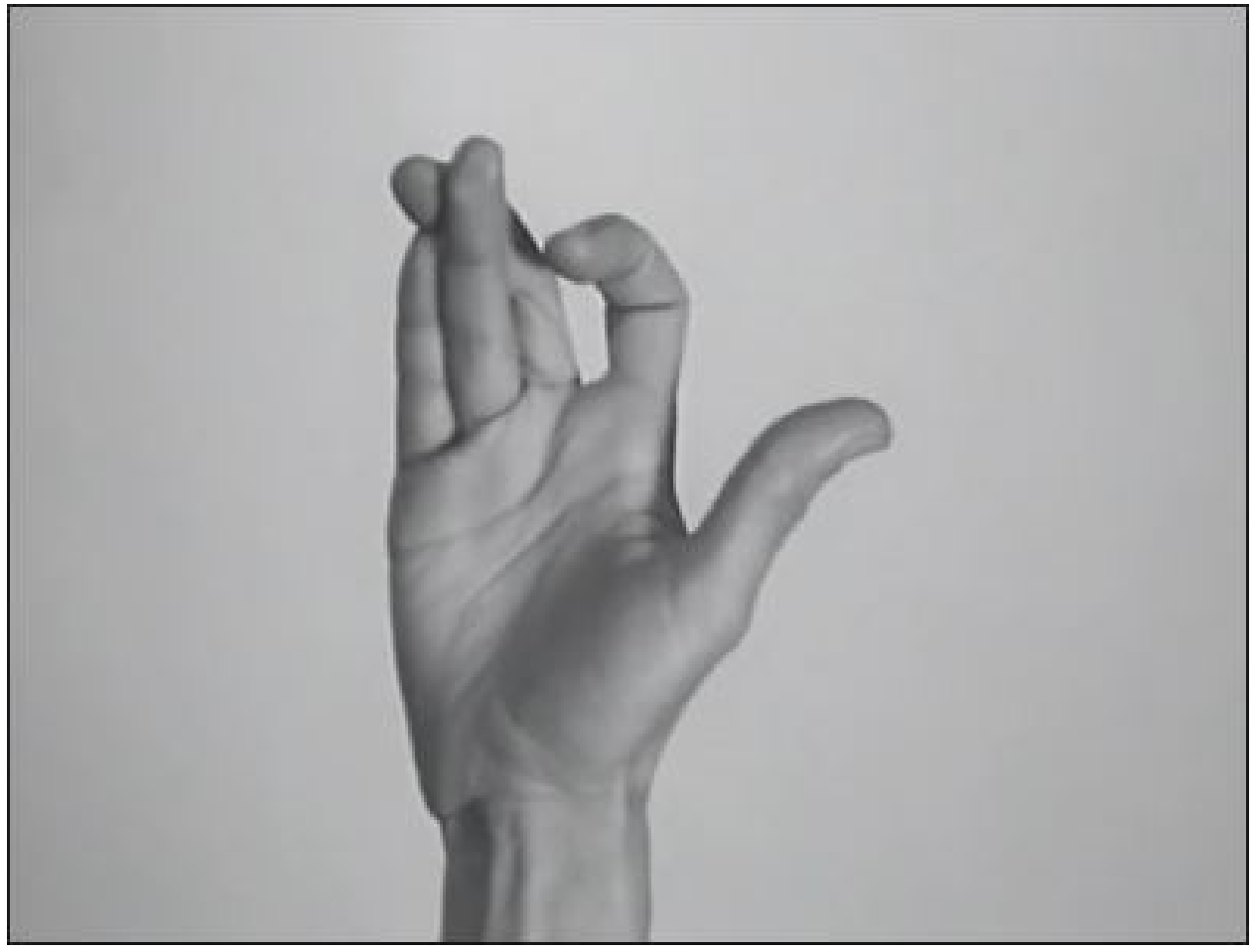

Yvonne Rainer's Hand Movie (1966). Camera: William Davis. Permission courtesy of the artist.

The hand, as Rainer reminded me in a recent email exchange, is that of a young woman, and she was surprised I had not remarked on the fact.23 Rainer was thirty-two at the time of the filming, and her comment raises issues of gender, age, and the historiography of living artists. Certainly it illuminates the gap between her original experience and intention in making the film and what historians and theorists 
retrospectively read into the work, or what she has called "writers' long-winded attempts to make anything more of the films," with the present text apparently included in that category. This gets at an important aspect of much of the work that was generated by the Judson Dance Theater, namely a focus on experimentation over archiving, where the short-lived nature of the live art form was pushed to the extreme.24

In terms of gender, it could be said that only through a comparison of the Rainer and Serra films does the gender binary become distinctly visible. Rainer scholar Carrie Lambert-Beatty has written that the hand in Hand Movie is not immediately identifiable as either male or female," 25 and when observed in isolation this might hold. But when a viewer considers the exploratory, gently probing and sensate movements of Rainer's hand, and contrasts them with the forceful grasping of falling pieces of lead in Serra's Hand Catching Lead, what Douglas Crimp has described as a "powerful male wrestling art from stuff," 26 a gender performance becomes effectively readable. This is nevertheless framed by Rainer's special status as one of the few women who has established a place for herself within the male-dominated canon of minimalism.27

One of the key ideas associated with Rainer's work of the period is the notion of the materiality of the body-the body as a material to work with, just as if it were plywood or steel. In her own words, Rainer questioned "how to use the performer as a medium rather than persona." 28 This approach can be seen as a development of choreographer Merce Cunningham's depersonalization of the performer, but which also signaled a rethinking of the body as the site of medium itself, an embodiment of the artist's materials. This specific notion of medium gains traction if we take on Lambert-Beatty's proposal that Rainer's hand in the film enacts an "avoidance of all ... kinds of signification." 29 The hand exhibits a semiotic opacity; the movements never crystallize into readable gestures - the fist never solidifies into a symbol of defiant power, the fingers never form a peace or victory symbol. The hand, Lambert-Beatty proposes, is reduced to a state of non-signification. I suggest this lack of transparency and readability calls attention to the very materiality of the hand; it represents nothing other than its physical, manual self. It can even be seen as exemplary of what Rainer described in the 1968 program for the Mind is a Muscle as the "unenhanced physicality" of the body.30

Where Rainer's Hand Movie unfolds along a temporal continuum of ever-changing movements, Serra's Hand Catching Lead is a three-minute exercise in reflex, repetition, and rhythm - a task-based experiment in which he attempts, and frequently fails, to catch falling pieces of lead. The 1968 film, like Rainer's Hand Movie from two years earlier, was Serra's first. He followed it with four more films that featured hands: Hand Lead Fulcrum (1968), Hands Scraping (1968), 31 Hands Tied (1968), and Frame (1969).32 Serra's move to film, synchronous with his written Verb List (1967-8), cinematically 
documents his shift from working with rubber in works like Scatter Pieces (1967), to lead with works like Slow Roll: For Philip Glass (1968), and his subsequent prop pieces. For Serra, this period was richly informed by the work happening at the Judson Church, particularly that of Rainer. Art historian Hal Foster has suggested that Serra's exposure to Judson led to the desymbolizing and desubjectivizing of his work, removing its representational function, and objectification, and taking the artist's hand out of the equation-an irony that both Rainer and Serra play with in their foregrounding of the hand as cinematic subject.3s Speaking of the Judson influence, Serra recalls that "dance and performance clarified a lot of what I wanted to do-I would go to Yvonne's performances and come home with more ideas how to proceed with than I found in the art world ... we were all into process at the time. It didn't matter whether you were a sculptor or a filmmaker or a musician." 34 This statement gets at the impulses that one artistic medium can give another, and characterizes a movement that results in the rethinking of medium-specific conventions, the prevailing ethos of the time. But it also raises interesting questions about the way the live arts can act as a catalyzing environment for the visual arts, as has been shown in twentieth century from the art-laden productions of Diaghilev's Ballets Russes to Merce Cunningham and John Cage's collaborations with Robert Rauschenberg and Jasper Johns. The deeper issue here points to the limits of influence within the classical aesthetic hierarchy of the arts, where historically the live arts have been crucial to the aesthetic development of the plastic arts, but have not always been acknowledged as such. 35

The movement in Hand Catching Lead remains the same from start to finish, yet Serra's failure to catch the lead provides an indeterminate aspect to an otherwise predictable exercise. The result: a movement system composed of a human hand and multiple lead objects. Notably, composer Philip Glass collaborated with Serra on Hands Scraping Lead, and Serra dedicated the sculptural work Slow Roll: For Philip Glass to the composer as well. This points to the potential of a musical reading of the film, where the repetitive continuous actions without climax can be seen as exemplifying certain tendencies within so-called 'minimalist' music, further illustrating the porosity of borders between media. 


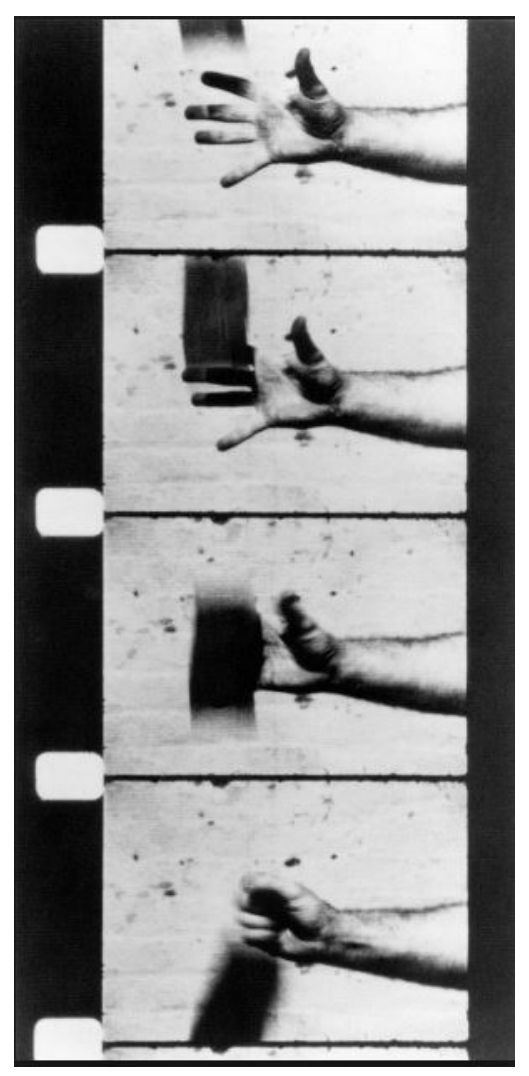

Richard Serra's Hand Catching Lead (1968). Permission courtesy of the artist.

Two movements structure the film. The first is the grasping action of Serra's hand as he attempts to catch the falling lead. The second is the piece of falling lead itself. The intersection of these two movements forms a dynamic horizontal and vertical axis. The tensing and releasing movements of the tendons in Serra's wrist make visible, at an intimate level, the minute process of the manual labor of the artist's body at work. The physicality of Serra's hand is noteworthy as it is enacted in a completely functional way. This appears to be a different strategy than that of Rainer, who on one level can be seen enacting a pure exploration of manual articulation as a relation of the bodyas-medium to itself, whereas the relationship of Serra's hand with the lead is a performative and process-oriented embodiment of the relationship of the artist with his materials.

Serra recalls seeing Rainer's Hand Movie, and her other early films at the Anthology Film Archives in New York. Along with seeing Andy Warhol's Chelsea Girls (1966), the films allowed Serra to "entertain" the prospect making his own films. Where Warhol's "detachment" made the medium appear accessible, Serra recollects he "felt a very direct relationship" with Rainer's films." 36 This detail is central to the discussion of movement between aesthetic categories and identities, as it was seeing the work of Rainer, an experimental choreographer, working in film for the first time, coupled with seeing Warhol's film, the work of an established visual artist, that inspired Serra to 
enact a media transgression himself, a jump from the realm of the object arts sculpture and painting to that of film. I suggest that this creative act also constitutes a movement between media, where artists working in diverse media act as catalyst for each other.37

\section{The Movement Image and Out of Field}

Gilles Deleuze wrote in 1986 that great filmmakers could be compared "not merely with painters, architects and musicians but also with thinkers," 38 placing film on par with philosophy as a knowledge-producing endeavor, and elevating it above its aesthetic relations. One idea he introduces is the "false movement" of the cinema, which is the way individual frames of a film run together sequentially to produce a seamless moving image. 39 Through this fictitious illusion of movement, a result of the aggregation of the individual images passing in a high-speed progression, what he terms a "movement-image" becomes possible. Like photo flip books, the movement is not associated with the single still images, but rather with the moving image they create by their viewing in rapid succession, mirroring the phenomenon of kinetic perception itself. What is interesting about his proposal is the way it draws attention to how movement is perceived in reality, where the condition of movement already structures our perception of it thoroughly. Deleuze draws the conclusion that film actually mirrors thought processes and perception, and the projected celluloid strip may be an approximate, material realization, of the way the mind apprehends the phenomenological world. I would like to propose that both Rainer and Serra's films are robust examples with which to engage this philosophical position-in different ways, and on their own terms. For our purposes, Deleuze's "movement-image" helps separate the levels of movement at work in the films: the event of the original hand movements performed for film, the illusion of Deleuze's "movement-image" generated by the individual images, and the actual physical movement of the filmstrip that a series of white spots on the celluloid make visible. 40 


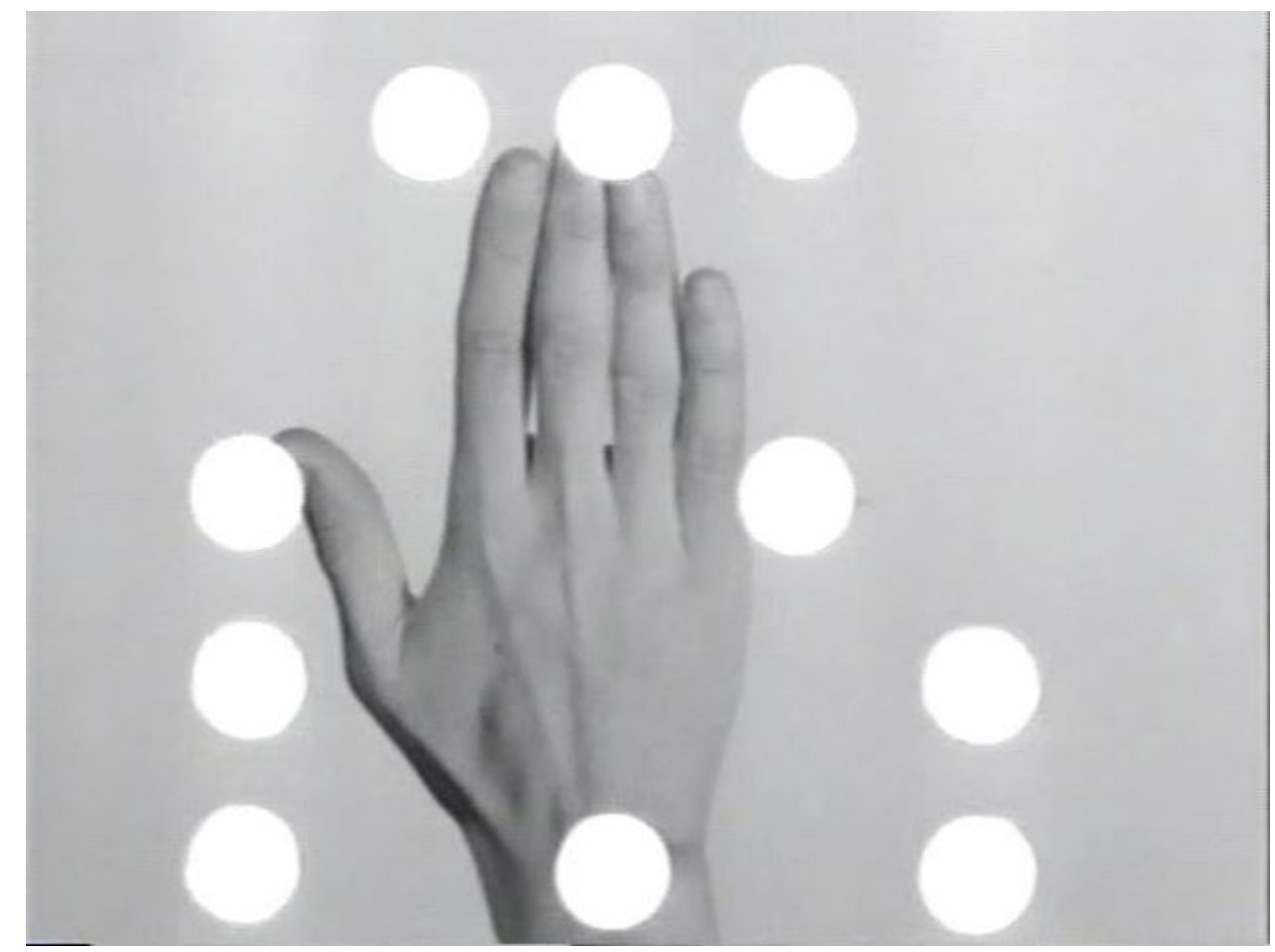

Yvonne Rainer's Hand Movie (1966). Camera: William Davis. Permission courtesy of the artist.

Two other aspects of movement analysis Deleuze introduces are his "theory of frame" and "out of field" (hors-champs). Using these theories allows me to suggest these films are fundamentally different instantiations of the way movement is captured within the rectangular edges of the frame. Yet where Deleuze tells us that the boundary of the screen image constitutes a closed system, and that what is transpiring within its borders can be thought of as an "information system rather than a linguistic one," I propose that in the case of these two films, the hand, with its gestural potential, resists reduction to the informative and instead inhabits a space of articulation and functionality. ${ }_{41}$ Nevertheless, the frame does provide information with its composition of static rectilinear lines and diagonals, within which the moving image stabilizes and balances itself. Deleuze suggests that what is inside the frame can be thought of in two ways: either as 1) a "dynamic-physical" information system that in reality extends beyond the frame, or 2) a "geometric" information system, in that its movements do not go beyond the frame, rather they emanate from it.42 The difference between these two perspectives posits movement as either pre-existing the frame dynamically and physically, or originating from the screen geometrically. The question is this: what can Deleuze's frameworks of analysis reveal about these works' underlying structures of movement?

The durational aspect and minimalist approach in both films can make Deleuze's theory of frame clearly visible, while simultaneously differentiating their cinematic ontology, allowing for a robust interpretation of the way movement functions in the 
works. And if we apply Deleuze's proposal, we do get some interesting results: Rainer's Hand Movie appears to fall into Deleuze's "geometric" concept of frame. Why? The upright position of the hand creates a stable vertical line, and although Rainer's wrist is cropped along the bottom edge, the movement is generally generated from the hand, which, apart from the few times she moves it laterally across the frame, is predominantly centered in the screen. Hence the hand movement is centrifugal and centripetal, directed both outwards and inwards. Considered as such, it appears that the movement in Hand Movie originates from the screen as opposed to prefiguring it-making it "geometric" in nature.

On the contrary, Hand Catching Lead can act as an illustration of Deleuze's "dynamicphysical" theory of frame. Although the action of Serra's grasping hand (and forearm) is centered in the setting, it nevertheless indicates a dynamic system of movement taking place outside the borders of what is visible. The falling pieces of lead point to an unseen source or origin. The fluctuation of movement in Serra's arm, as he grasps the falling pieces, suggests a whole-body effort is at work to achieve the framed effect, and in this sense the work appears to be "dynamic-physical" in nature.

With this theory of frame it is possible to see that although these two films can initially be seen as optically similar, they are actually very different instantiations of filmed movement. This is important as it not only complicates the artists' relationships with the conventions of their respective media, but it also reveals how these works are exemplary in their embodiment of the interdisciplinary nature of the works of the period, specifically the way the object arts borrowed aspects from the temporal arts, and vice versa.

Deleuze expands his theory of the frame with the notion of the "out of field," which posits that an image is only a subset of what exists outside of the borders of the shot. Herein lies another conceptual movement. The "out of field" necessitates a viewer's mental shift outside the frame, and then back into it. As both films feature a cropped image of the hand that excludes the rest of the body, the theory is particularly pertinent to this analysis. By considering what exists in the "out of field," it is possible to include the dynamics of what is not seen with the interpretation of what takes place within the frame.

That Rainer's and Serra's bodies are unseen is not, therefore, a negation of them. Rather, this absence can become in Deleuzian terms "perfectly present." 43 So considered, Rainer's immobile body recovering from surgery, the hospital bed and room, along with her Judson colleague William Davis filming the scene, all become components in the analysis and interpretation of the film. In this sense Rainer's hand becomes a synecdoche, the part that reflects the whole of the entire hospital scene. Considering the "out of field" in Hand Catching Lead is equally productive. The physical system arranged by Serra, with the dropping the pieces of lead must have been an 
exhilarating choreography of movement, object, and rhythmic components. Where Rainer's "out of field" is static due to incapacitation, Serra's "out of field" is kinetic and dynamic, again suggesting a reversal of medium between the more static nature of the object arts and the physically kinetic nature of the performative arts. Applying Deleuze's formalist analytical concepts to Rainer and Serra's films reveals unseen movements hidden within their structure that allows for a novel rethinking of their aesthetic identity. I now turn to Jerrold Levinson's account of hybrid art forms, which offers a precise and historically contextualized way of thinking about the interaction and synthesis of artistic media such as can be seen in Hand Movie and Hand Catching Lead.

\section{Aesthetic Hybridity, Historical Context, and Indeterminacy}

Levinson suggests that art forms are considered 'hybrid' when they can be decomposed conceptually into two or more distinct artistic activities or ostensible media.44 This definition gains traction with the works under consideration. He additionally proposes the need to understand the historical context - not the structural or material composition - to determine if a work is hybrid. Levinson explains: "hybrid status is primarily a historical thing as is...being a biological hybrid. An art form is a hybrid one in virtue of its development and origin, in virtue of its emergence out of a field of previously existing artistic activities and concerns." 45 I agree that the historical aspect is key in identifying both Hand Movie and Hand Catching Lead as hybrid forms, cases where the artists have combined their respective artistic media with the new medium of film. In order to understand what Rainer is doing with her hand as an instance of the dance medium, and what Serra is doing as occurring within the plastic arts, it is necessary to have followed the historical development of their respective media, and how they chose to respond to its conventions at that particular moment in time. For Rainer, it was a concern with the materiality of the body and functional, selfcontained movements that resisted phrasing, transitions, or overt theatricality. For Serra it was a concern with the way materials interacted with the process of artmaking, and how this became visible in residual forms that purposely defied mediumspecific definitions.46

Even for works that are not hybrids, a knowledge of the history and theory of the practice is often needed to identify if something is art at all, let alone a hybrid.47 Think of Marcel Duchamp's Fountain (1917) or Andy Warhol's Brillo Boxes (1964) as optically indiscernible from their non-art counterparts. It is only through acculturation and knowledge that a viewer of these works is able to see past their potentially misleading forms to understand how they each signified a revolution in the history of representation.48

As if to offer a counter-model of analysis, Levinson suggests another more flexible lens with which to look at works of art as ahistorical hybrids, that is as if they were a 
combination of certain media, which he calls "Gedanken" (thought) hybrids.49 This ahistorical model is significant, as I propose it implies both direction and choice for the viewer in the identification process, supporting my thesis that conceptually speaking, hybrid media can be seen as in a particular kind of movement not only in their production but also in their mode of reception. Levinson provides three main models for classifying various types of ahistorical hybridity: the juxtapositional, the synthetic, and the transformational. Levinson proposes a silent movie as an example. This is apt, since both Hand Movie and Hand Catching Lead at least initially possess aspects of the silent movie form. Where Levinson determines that a silent movie is composed of photography and theatre, I suggest that Hand Movie can be seen as being made up of photography and dance-but is it not also potentially sculptural? Or performance art? Hand Catching Lead is an equally complex combination, of photography for sure, but what are the additional constituent media? Painting? Sculpture? Hal Foster has referred to this film as a "sculptural film" but Serra has resisted this categorization by arguing that even when aesthetic languages can be shared by artists working in diverse media, the "basic assumptions of film" as a two-dimensional illusionistic "plane" has no sculptural potential whatsoever, and any attempt to speak about his work (by Foster) in that way is "nonsense." 50

For Levinson, the question is if a silent movie is a synthetic or transformational hybrid. He concludes that it is synthetic; for in order for it to be transformational, an entirely new medium needs to have arisen out of the combination. This is where it gets interesting and somewhat tricky; the understanding of the silent movie's hybridity can move in either direction of its constituent media, and Levinson then argues that the silent movie can be seen either as a "kinetic photograph" or a "non-bodily theatre." 51 Thus considered, Rainer's Hand Movie is also synthetic, as its hybrid identity can move either in the direction of dance, as a dance film, or in the direction of an experimental film that features the hand of a dancer. Hand Catching Lead is equally synthetic, moving between the object and performance arts even in light of Serra's comments above on Foster's proposal of "sculptural film." In both cases, a new medium has not arisen out of these hybrids. Yet the option for the viewer to move directionally toward different constituent media elucidates one of my key claims concerning the movement of media, and how within hybrid forms, an indeterminacy exists that asks that different media be considered as constituent, a request of the viewer that brings the aesthetic components of a hybrid into a dynamic state of flux.

An interpretive question then ensues: what kind of meaning arises from an artwork whose aesthetic identity is in flux due to the indeterminate status of its medium? I propose that an indeterminate media identity destabilizes and makes us question the very means through which the content is received, and therefore by which it might be recognized. This moment of indecision when confronted with the task of aesthetic classification is crucial for three reasons: 1) It firstly calls attention to the way our 
concepts for artistic media are both socially constructed and historically conditioned-in this case, the medium of film (shot on Super 8 and $16 \mathrm{~mm}$ cameras) frames both Rainer and Serra's projects as being of their particular historical and technological moment, while interrogating their status in relation to the plastic and performing arts. 2) It gives agency to the viewer, which allows them to activate their own knowledge of the history and theory of the arts, and make their assessment of what artistic media are at play. And 3) it gets at the protean aspect of an art work as a form of representation that is full of aesthetic potential, and can arguably be perceived as many works of art at once when considered in the iterations brought about by the indeterminacy of the hybrid form.

By acknowledging the inherent potential within hybridity and creatively choosing to receive the same content through different artistic channels, I suggest new meanings arise from a work that initially appeared to bound by a single aesthetic concept, i.e. experimental film. In the case of Hand Movie, and Hand Catching Lead, film, performance art, sculpture, painting, and dance, can all be considered as constituent media. I suggest the meaning of the work multiplies to the degree that each medium involved adds its own particular history and conventions to the reading. Additionally, Rainer and Serra's films can be read and theorized fully from the various disciplinary perspectives such as art history, dance studies, and film studies. This leads me to propose that the aesthetic and disciplinary confluence actually allows the works themselves to move simultaneously within multiple artistic discourses. This highlights a heretofore unseen way in which there is a discursive movement at work in relation to the hybridized aspects of these films. I now want to move the discussion away from ideas of hybridity and indeterminacy within Rainer and Serra's works, and towards another theoretical terrain, one that looks at artworks in terms of their intermediality. I focus particularly on how language from intermedial studies can enrich the discussion and bring it toward a final stage of theoretical abstraction. Although there is some conceptual overlap with Levinson's proposals, using the intermedial as a framework for Hand Movie and Hand Catching Lead provides an analytical approach that supports my movement thesis by allowing for a spatialized conception of the way artistic media dynamically interrelate.

\section{Intermedial Turns}

The prefixes inter-, intra-, and trans- are remarkably kinetic, especially when coupled with the word medial, (i.e. intermedial, intramedial, and transmedial). These terms, drawn from intermedial studies, allow for a further development of my movement thesis, namely that an examination of the movement implied in the words themselves opens up a dynamic theoretical space around, across, and between media. This is a theoretical jump. Nevertheless, I want to forward the idea that by mentally opening up this abstract space, a theory of displacement can enter the discussion. I suggest that this notion can make another strata of movement visible in Rainer and Serra's films 
such that the configuration of the media of dance, film, painting, sculpture, and performance art are can be seen as in a state of continuous displacement. First, some historical background on the critical study of intermediality 52 undertaken within the German academy since the 1990s will help to situate my argument.53 At the tail end of a long-standing tradition of interart studies 54 is what has come to be known as the "intermedial turn." 55 Irina Rajewsky provides a brief contextualization of this turn. She has proposed that intermedial studies offers new ways of thinking about both the "medial border crossings and hybridization" and "materiality" that has been evidenced within current artistic production. 56

Rajewsky describes two current debates within intermedial studies useful to the present discussion. The first debate is epistemic, that is, based in the knowledge of art media and how we can recognize them as such by mentally cross-referencing intermedial artifacts under analysis. For example, how is a performance of a minimalist work like Hand Movie related to dance, or Hand Catching Lead to painting or sculpture? Like Levinson's historical context, an external referent is needed to make such an identification. The second debate is both epistemic and ontological as it deals with the knowledge of the artistic forms as well as their structural differences. At issue is whether it is only through the relationship between various media that an individual medium is made visible. 57 In this sense, the fact that Hand Movie is framed within the medium of film makes the gestural and performative elements of the hand, and the history (and disavowal) of theatrical dance that it arguably embodies that much more apparent, while simultaneously calling attention to the film medium as starkly different from that of Rainer's choreographic experiment for the camera.

Looking at the terminology used by scholars in intermedial studies shows close similarities to Levinson's hybrid forms, but also productively expands the vocabulary. Rajewsky offers a technical breakdown of intermediality into discrete parts that include transmediality, remediation, and the plurimedial.58 Where intermediality deals with the crossing of borders between media, transmediality is the way a "certain motif, aesthetic, or discourse" can appear across diverse media.59 The plurimedial model can be seen as analogue to Levinson's juxtapositional model, in the sense that the media involved remain true to their original form. Remediation can be seen as comparable to Levinson's transformational model when a whole new medium is created. Adding to these terms are proposals such as intramedial transposition, illustrated with the example of an adaptation from stage to screen.

Considering Hand Catching Lead within an intermedial framework, I propose that it is both inter- and intramedial, that is, medially between and inside sculpture, performance, and film. Taking the intermedial perspective, Serra grasps the material of sculpture, the lead, but does not create a static sculptural object. The process aspect is revealed in a repetitive and performative sequence. Film is the container for the activity, but rather than encompassing the constituent media completely, it points to 
them from a space in between. I would also add that it gestures towards the objectoriented conventions of 1960s dance due to the influence of Rainer's film and performance work. On the other hand, as an intramedial work, I suggest that Hand Catching Lead takes place completely within the medium of film, as well as fully within the sculptural tendencies of repetition of the period directly preceding the making of the film, 60 and hence is fully "inside" of these media. As has been previously established, I am making a case that discerns the heretofore unseen movements of and between media, not only optically and physically, but also theoretically. By applying the inter and intramedial models to Hand Catching Lead, I further assert that the constituent media of the film can begin to be conceptualized in spatial terms, and within this space it becomes possible to envision new configurations and constellations of media in movement.

At this point the language of the intermedial has established a more specific structural framework with which to consider the movement between, within, or across media. I want to push this idea further and propose that due to this spatialziation of media in movement, a theoretical space or gap between the individual media becomes apparent. I have addressed the potential meaning of an artwork that has an indeterminate aesthetic status by arguing that it calls attention to the various media of which it is composed as forms of representation. I have not yet addressed the issue of what is implied in this space or gap between media. Perhaps the space is a space of non-representation from which representation draws its content, or the edges of its abstract form. Or, it is a space of pure potential and possibility that preexists medial formations before they cohere as social and aesthetic constructs.

Philosopher Lydia Goehr has suggested a theory of displacement that can gain traction here. The theory supposes that it is not a dissolving of distinctions between media that is the issue with hybridity or intermediality, or in her case between music and film. Rather it can be seen as an act of medial displacement, where in the new configuration a fluid yet tenuous relationship between the original media remains.61 She further suggests that the potential meaning generated by this displacement has social implications. The dissolution of aesthetic boundaries, where former differences between traditional media have been erased is a reflection of a society and culture where all distinctions have been eroded, and where art itself has been displaced.62 The notion of displacement that takes place in the conceptual space of media brings a new dynamic to the discussion, as this becomes a theoretical space of risk where moving across, through or between its interstices can be aesthetically dangerous and socially emancipatory, opening new perspectives by displacing the old ones.

To return to Hand Movie, I propose that it is possible to perceive just such a medial displacement at work. Rainer has displaced the dancer with a hospital patient (herself) the body with the hand, and dance with a choreographic experiment. The move into the two-dimensional realm of film displaces the live performance of gesture and 
replaces ephemerality with persistence. In Hand Catching Lead, Serra, the sculptor, has been replaced by a performer, the sculptural object by the process of its making, and the three-dimensional sculptural object has been collapsed, displaced by the twodimensional image of film. In both cases, a series of displacements has been enacted on the practical level that not only has theoretical ramifications, but that also illustrates how the tension between the displacing and displaced forms remains in a delicate yet taut relation.

\section{Conclusion}

The final question now is this: how does the arrival at a theory of displacement reflect back on the trajectory that the discussion has taken? Dance aesthetics requires that we show how movement gets translated into concepts, and in this article in particular, into medium. I propose that the movement to medium creates a displacement that is parallel to the displacement from the empirical to the theoretical that has been undertaken in this article, where the act of displacement becomes a form of reflection and critique. I set out to argue that movement is as an overarching thematic of the films, dynamically structuring the various analyses, viewpoints, proposals, and theories gathered together. What has been revealed in this process is that movement is also the underlying force of the conceptual framework that has been developed along the way. That is, there are two clear lines of movement generated thought that travel along parallel and at times overlapping empirical and theoretical tracks. From Deleuze's cinematic ontology that analyzed the original movements and actions by Rainer and Serra, to the movement of the film strip itself, and the notion that movement is a cinematic illusion, I began to question the assumptions of where movement might lie hidden in plain sight in the films, a necessary foundation upon which more abstract thinking would be possible later.63 What became clear in the first section of this article is that when movement is analyzed both empirically and ontologically, a level of detail becomes visible that reveals the underlying kinetics of the films themselves as embodiments of the interdisciplinary ethos of their period. I also suggest that it can change the very way movement is perceived and understood in daily life.

The discussion of hybridity brought a new element of synthesis into the conversation. Levinson's proposal to ground the analysis of a hybrid within a historical context not only allowed me to make the connection of Rainer's hand movements to dance and the choreographic, and Serra's catching pieces of lead to the art of painting and sculpture, it also provided the idea that an external referent is necessary to identify the component media of a hybrid. This gets at another aspect of movement that travels along the path between the object of analysis and its history. By identifying indeterminacy as an effect of hybridity, I proposed that to cognitively move toward the constituent media of a hybrid, its' identity is destabilized. What is novel here is the way that the cognitive, or mental movement involved in thinking about the constituitive 
media of a hybrid begins to get at their abstract form. The language of the intermedial provided the next crucial intellectual step; to begin to see how aesthetic media in abstraction can be seen as if in movement themselves, which also had a spatialzing effect on the concepts. Once the media are in movement, the negative space between and around them comes into stark contrast, and that ultimately provides a field where a theory of displacement can come into play. As an original critical and reflective perspective, a previously unseen dimension of medial form and content in Rainer and Serra's aesthetic displacements is revealed, one that transits between the space of the practical, the social, and the theoretical-a place where media behaves and moves in strange ways, and artists experiment with their bodies, materials, and aesthetic alterity, while always maintaining a tenuous and fragile dialectical relation to what they know, and who they were before.

\section{Biography}

Kyle Bukhari studied Anthropology \& Aesthetics at Columbia University, and Dance Studies at the University of Roehampton, London where he was the 2013-14 US-UK Fulbright Fellow in Dance. He has danced with the Joffrey Ballet, New York, and the Zurich Ballet, Switzerland and was a winner of the Best German Dance Solo (1998). In 2013 Kyle choreographed and performed at the Whitney Museum, New York with anthropologist Michael Taussig and currently collaborates with New York choreographers Jodi Melnick and Yanira Castro. He has presented his research in the philosophy of dance at Columbia University, University of Ghent, Belgium, University of Groningen, Holland, Video Art Festival Camaguey, Cuba, and the Center for Ballet and the Arts at NYU. Kyle is on the faculty at Sarah Lawrence College, New York.

\section{Email:kbukhari@sarahlawrence.edu}

\section{Notes}

1 See also Douglas Rosenberg's "Introduction" in The Oxford Handbook of Screendance, 9-10. Rosenberg places these films in relation to suggest they are exemplars of expanded cinema and media "boundary crossing" with the screen as the site of transgression.

${ }_{2}$ Carrie Lambert-Beatty, "Other Solutions," 49.

з Benjamin Buchloh, "Process Sculpture and Film," 5. 
4 Douglas Crimp, "Sculpture Exceeded," 71.

5 Yvonne Rainer's Hand Movie is from a set titled 5 Easy Pieces, and is the only one to feature her hand. Serra's hand or hands appear in five of his films of the period.

${ }_{6}$ Hal Foster, "To Support," 8.

7 Richard Serra created works featuring live animals in Live Animal Habitat (1965-66) at the Galeria La Salita, Rome, 1966 while on a Fulbright fellowship.

${ }_{8}$ Buchloh, 5 .

9 lbid.

10 Art historian Rosalind Krauss provides another perspective on how medium has been conceived within the discourse of art history, namely in terms of genre and material support ("Two Moments from the Post-Medium Condition," 56). I understand this as a combination of both the actual physical materials used (Krauss uses the word 'substance'), such as oil and canvas for painting, cast bronze or metal for sculpture, combined with the conventions and tradition of a plastic arts practice. Yet for Krauss, this is a reductive and outmoded way of thinking about medium; she opts for the idea of 'technical support,' as it reflects the complexity of the new technologies being utilized by artists that often make it difficult to determine what material support is actually in place (Ibid.). Krauss has additionally suggested that we are now in a paradigm of the 'post-medium,' particularly with the rise of installation art.

11 Walter Benjamin, "The Work of Art," 19.

12 Marshall McLuhan, "The Medium is the Message," 7.

13 J. David Bolter and Richard Grusin, Remediation, 4.

14 Rainer studied modern dance with Martha Graham, Merce Cunningham, and Anna Halprin, African dance with Louise Gilkes, and ballet with Nina Strogonava, among others. Serra received his MFA in painting in 1964 from Yale.

${ }_{15}$ Gilles Deleuze, The Movement Image, 12.

16 Jerrold Levinson, "Hybrid Art Forms," 5.

17 Irina Rajewsky, "Intermediality, Intertextuality, and Remediation," 44.

18 Lambert-Beatty, 310, endnote 46.

${ }_{19}$ Rainer in email to author.

20 Rainer has written that the "No Manifesto ... was never meant to be a prescriptive for all time ... but rather ... [to] clear the air at a particular cultural and historical moment ..." Feelings are Facts, 264.

${ }_{21}$ Hand Movie was also screened as part of Rose Fractions (1969) at the Billy Rose Theatre in New York, only to be infamously replaced after opening night with a pornographic film.

22 Lambert-Beatty, 173.

23 Rainer in email to author.

24 Others who were not part of Judson, such as Twyla Tharp, documented their work of the period extensively. 25 Lambert-Beatty, 173.

${ }_{26}$ Crimp, 71. 
27 Anna Chave, "Minimalism and Biography," 149. Chave's discussion of the gendered lines along which Minimalism has been discursively formed is apt for the discussion of gender and subjectivity within Rainer and Serra's works.

${ }_{28}$ Rainer quoted in Lambert-Beatty, 167.

29 Idem. 173.

30 Rainer "Statement" from The Mind Is a Muscle program, Anderson Theater, New York (April 1968); reprinted in Work, 1961-73, 71.

${ }_{31}$ Hands Scraping (1968) was notably made in collaboration with the composer Philip Glass. See Annette Michelson, "The Films of Richard Serra," 72.

32 Also within this vein of hand iconography is the color film Color Aid (1970-71) featuring Serra's dirtied fingers and colored cards.

${ }_{33}$ Foster, 8.

34 Idem, 16, note 6. See also Serra in McShine "A Conversation About Work with Richard Serra," 25-26.

35 In Rosalind Krauss' Passages in Modern Sculpture, Serra's Hand Catching Lead opens the final chapter with no mention of Rainer's influence on Serra, although Krauss does hesitantly mention Rainer's insistence on "the parallels between the sensibility of the new dance and that of minimalist sculpture" in an earlier chapter. Krauss, 243, 236.

${ }_{36}$ Serra quoted in Michelson, 68 and 74.

37 Movement between media aside, it is the shared iconography of the hand in Rainer and Serra's films that is noteworthy, particularly as this type of hand-focused image, cropped tightly within a frame, is not without precursors in film. Jean Cocteau's surrealist masterpiece The Blood of a Poet (1930) featuring the speaking hand of the tormented artist can be seen as prefiguring both Rainer and Serra's films.

38 Deleuze, 1.

39 Idem, 2.

40 We could also include the movement of the Super 8 Camera machinery, as well as the movement of the film projectors that were used to screen the films before they were ultimately digitized.

41 Idem, 12.

42 Idem, 13.

43 Idem, 16.

44 Levinson, 5.

45 Idem, 6.

${ }_{46}$ Foster, 7.

47 See Arthur Danto, "The Art World."

48 Idem, 8.

49 Levinson, 6.

50 Serra quoted in Michelson, 73. Even when Krauss refers to Serra at the time as a "young sculptor" (Passages in Modern Sculpture, 243), I would also venture in light of Serra's comments that referring to Hand Catching Lead as a sculptural film is a retroactive projection of Serra's later artistic identity as a sculptor on to his 
experimental and mixed media works of his earlier period of production where his artistic identity was consciously protean.

51 Levinson, 11.

52 Sabine Huschka proposes a "movement specific intermediality" ("Media-Bodies," 61) as a way of thinking about William Forsythe's performance installations that is of interest but beyond the scope of the current work here. She offers a concept of intermediality that is focused on the body of the performer and audience as sites of image and linguistic production, and sensory experience of space.

53 The disciplinary questions and problems within the field of intermedial studies are not new. The intermedial debate can as be seen as analogous to the debate in literary theory emerging out of Mikhail Bakhtin's dialogism and Julia Kristeva's intertextuality. 54 Rajewsky, 44.

55 Werner Wolf, "(Inter)mediality and the Study of Literature," 2.

56 Rajewsky, 44. Rajewsky's case study is German choreographer Sasha Walz's Körper (2000).

57 Rajewsky, 48.

58 Idem, 5.

59 lbid.

60 Krauss, 244.

61 Lydia Goehr, "Three Blind Mice," 208.

62 Idem, 231.

63 This first step was also an aesthetic set up that can be traced to my interest in the philosopher Arthur Danto's theory of indiscernibility in relation to Rainer's pedestrian dance works and how things that appear to be optically and ontologically indiscernible can actually have a deeply divergent identity. Where Danto's theories are suitable for the often static nature of the object arts, Deleuze's theories are highly kinetic and more suitable for the time-based arts.

\section{References}

Benjamin, Walter. "The Work of Art in the Age of its Technological Reproducibility: Second Version." In Michael W. Jennings, Brigid Doherty, and Thomas Y. Levin (Eds.), Edmund Jephcottet (Trans.) The Work of Art in the Age of Its Technological Reproducibility, and Other Writings on Media. Cambridge: Harvard University Press, 2008: 19-55.

The Blood of a Poet. Dir. Jean Cocteau. 1930. Film. YouTube.

https://www.youtube.com/watch?v=RomiXOYTqKI 
Bolter, J. David and Richard A. Grusin. Remediation: Understanding New Media. Cambridge: MIT Press, 1999.

Buchloh, Benjamin H.D. "Process Sculpture and Film in the Work of Richard Serra." In Hal Foster and Gordon Hughs (Eds.) Richard Serra, OCTOBER files. Cambridge: MIT Press, 2000 [1978]. 1-20.

Bukhari, Kyle. "Embodiment of the Ordinary in Yvonne Rainer's We Shall Run (1965)." Unpublished essay. 2013.

Burt, Ramsay. Judson Dance Theatre: Performative Traces. New York: Routledge, 2006.

Chave, Anna C. "Minimalism and Biography." The Art Bulletin 82.1 (2000): 149-163. https://doi.org/10.2307/3051368

Crimp, Douglas. "Sculpture Exceeded." October 18 (Autumn 1981): 67-78.

Danto, Arthur. "The Artworld." The Journal of Philosophy 61.19 (1964): 571-84.

https://doi.org/10.2307/2022937

Deleuze, Gilles. Cinema 1: The Movement Image. Trans. Hugh Tomlinson and Barbara Habberjam. Minneapolis: University of Minneapolis Press, 1986.

Foster, Hal. "To Support." In David Frankel (Ed.) Richard Serra: Early Work. New York: David Zwirner, 2013.

Four Pieces by Morris. Dir. Babette Mangolte. Chor. Robert Morris. 1993.

http://www.babettemangolte.org/film1993.html

Goehr, Lydia. "Three Blind Mice: Goodman, McLuhan, and Adorno on the Art of Music and Listening in the Age of Global Transmission." New German Critique 35.2/104 (Summer 2008): 1-31.

----. Elective Affinities. New York: Columbia University Press, 2008.

Hand Catching Lead. Dir. Richard Serra. 1968. Film. YouTube

https://www.youtube.com/watch?v=_NBSuQLVpK4

Hand Movie. Dir. Yvonne Rainer. 1966. Film. YouTube https://www.youtube.com/watch?v=CuArqL7r1WQ

Huschka, Sabine. "Media-Bodies: Choreography as Intermedial Thinking Through in the Work of William Forsythe." Dance Research Journal 42.1 (Summer 2010): 61-72. https://doi.org/10.1017/S0149767700000838

Krauss, Rosalind. Passages in Modern Sculpture. Cambridge: MIT Press, 1998 [1977]. 
----. A Voyage on the North Sea-Art in the Age of the Post-Medium Condition. New York: Thames and Hudson, 1999.

----. "Two Moments from the Post-Medium Condition." October 116 (Spring 2006): 5562.

Lambert-Beatty, Carrie. "Moving Still: Mediating Yvonne Rainer's 'Trio A."' October 89 (Summer 1999): 87-112.

----. "Other Solutions." Art Journal 63.3 (Autumn 2004): 48-61.

https://doi.org/10.1080/00043249.2004.10791134

----. Being Watched: Yvonne Rainer and the 1960s. Cambridge: MIT Press, 2008.

Levinson, Jerrold. "Hybrid Art Forms." Journal of Aesthetic Education 18.4 (Winter 1984): 5-13. https://doi.org/10.2307/3332623

Lovatt, Anna. "Ideas in Transmission: LeWitt's Wall Drawings and the Question of Medium." Tate Papers 14 (2010). http://www.tate.org.uk/research/publications/tatepapers/ideas-transmission-lewitts-wall-drawings-and-question-medium

McLuhan, Marshall. "The Medium is the Message." Understanding Media: The Extensions of Man. Cambridge: MIT Press, 1994 [1964]: 7-21.

McShine, Kynaston. Richard Serra Sculpture: Forty Years. New York: Museum of Modern Art, 2007: 25-6.

Michelson, Annette. "The Films of Richard Serra: An Interview." In Hal Foster and Gordon Hughs (Eds.) Richard Serra, OCTOBER files. Cambridge: MIT Press, 2000 [1979]. 21-57.

Morris, Robert. "Notes on Dance." In Mariellen R. Sanford (Ed.) Happenings and Other Acts. London and New York: Routledge, 1995. 168-172.

Phelan, Peggy. "Yvonne Rainer: From Dance to Film." A Woman Who: Essays, Interviews, Scripts. Baltimore: John Hopkins University Press, 1999. 3-17.

Rainer, Yvonne. "Some Retrospective Notes on a Dance for 10 People and 12 Mattresses Called 'Parts of Some Sextets,' Performed at the Wadsworth Atheneum, Hartford, Connecticut, and Judson Memorial Church, New York, in March, 1965." The Tulane Drama Review 10.2 (Winter 1965): 168-178. https://doi.org/10.2307/1125242

----. Work 1961-73. Halifax: Nova Scotia School of Art and Design Press, 1974.

----. Feelings are Facts, A Life. Cambridge: MIT Press, 2006. 
----. Personal conversation with author at Dia Beacon, New York. May 13, 2012.

----. "Re: Article on Hand Movie." E-mail to author. October 14, 2016.

Rajewsky, Irina O. "Intermediality, Intertextuality, and Remediation: A Literary

Perspective on Intermediality." Intermédialités 6 (Autumn 2005): 43-64.

https://doi.org/10.7202/1005505ar

Rosenberg, Douglas. "Introduction." The Oxford Handbook of Screendance Studies. New York: Oxford University Press, 2016. 9-10.

https://doi.org/10.1093/oxfordhb/9780199981601.013.37

Wolf, Werner. "(Inter)mediality and the Study of Literature." CLC Web. Comparative Literature and Culture 13.3 (2011): 1-9. https://doi.org/10.7771/1481-4374.1789 